\title{
DELAROSE: A Case Example of the Value of Embedded Course Content and Assessment in the Workplace
}

\section{Wells, John S.G ${ }^{\text {a }}$ Bergin, Michael ${ }^{\mathrm{b}}$ and Ryan, Cathal $^{\mathrm{c}}$}

${ }^{a}$ Head of School of Health Sciences, Waterford Institute of Technology, Ireland, ${ }^{b}$ Lecturer, Department of Nursing \& Health Care, Waterford Institute of Technology, Ireland, ${ }^{c} \mathrm{PhD}$ Scholar, Department of Nursing \& Health Care, Waterford Institute of Technology, Ireland.

\begin{abstract}
In recent years there has been a significant growth in online learning and the delivery of joint programmes of education involving collaborative partnerships between higher education institutions in different jurisdictions. This paper details a case-study of the pilot delivery and assessment of a new online learning programme 'Certificate in the Management of Work-Related Stress'. This programme was developed as part of an innovative partnership between four European Higher Education Institutions (HEIs) located in Austria, Ireland, Switzerland and the United Kingdom to develop and deliver an accredited online learning programme, as part of a wider EU funded project called DELAROSE, on the management of work-related stress for workers in the health and social care sector across Europe. It describes the nature of the online course, with particular attention given to, the assessment activities undertaken by learners throughout the course, and the collection and analysis of learner feedback as this relates to feasibility and impact of the programme of learning. This case-study highlights the positive benefits to learners of embedding course content and assessment experiences within a real-life workplace context.
\end{abstract}

Keywords: Work-based learning, embedded assessment, innovation, collaboration. 
DELAROSE: A Case Example of the Value of Embedded Course Content and Assessment in the

Workplace

\section{Introduction}

The DELAROSE project brought together three European HEI's - Waterford Institute of Technology in Ireland, University of Graz in Austria and the University of Applied Sciences and Arts of Southern Switzerland - in a collaborative partnership to develop and deliver an accredited online learning programme: the 'Certificate in the Management of Work-Related Stress'. This programme was delivered in pilot form to a sample of learners from the health and social care sector by these three HEIs in the English, German and Italian languages respectively. A fourth HEI, King's College London in the UK, collaborated in the development of the course material but at present does not deliver the programme to learners.

The DELAROSE project derived from the findings of a previous project, ROSE, which explored work related stress across Europe in the health and social care sector (Wells, Denny, \& Cunningham, 2011; Ridge et al., 2011). Stress at work is a considerable public health challenge across Europe (European Commission, 2011), with nearly $80 \%$ of managers in Europe concerned about stress in their workplace (ESENER Survey, EASHW 2010). A recent EU Framework Directive 89/391 now places a legal obligation on employers to protect workers by anticipating, evaluating and combating health and safety risks in the workplace. Furthermore, several other policy initiatives such as the 2008 European Pact for Mental Health and Well-being encourage employers to promote positive mental well-being in the workplace. However, the impact of these measures appears to be limited. For example, less than $30 \%$ of European workplaces currently have procedures in place to combat occupational stress, while $42 \%$ of managers' report dealing with psychosocial risks to be more challenging than other risks in the work-place (EASHW, 2010).

Health and social care have consistently been ranked as amongst some of the most stressful fields in which to work (Wells, 2011). Those working in these fields experience the highest rates of work-related anxiety, stress and depression in any field (Health and Safety Executive, 2014). Recent trends in the health and social care sector in Ireland, such as an employment moratorium, salary cuts and increased working hours have contributed an increasingly stressful and demanding work environment and a high level of staff turnover (Wells \& White, 2014).

The following paper presents a case-study of the delivery and assessment of the pilot online learning programme 'Certificate in the Management of Work-Related Stress'. It describes the nature of the online course, with particular attention given to the development of the assessment activities undertaken by learners throughout the course and the collection and analysis of learner feedback as this relates to feasibility and impact of the programme of learning. This case-study highlights the positive deep learning impact that can be made 
upon learners by locating their assessment experience within a real-life context that is relevant to their day to day experience.

\section{2. 'Certificate in the Management of Work-Related Stress'}

The DELAROSE online learning programme was piloted with a small sample of learners from the health and social care sector between June and September 2015. A total of 15 learners completed the pilot of the DELAROSE online learning programme across the three partner institutions. 7 learners completed the programme with WIT, while 3 learners completed the programme with SUPSI and 5 with the University of Graz.

The content of the programme consisted of Units of Learning Outcomes divided across two modules. Each module was worth ten ECTS credits. The first module, Person-Centred Management of Work-Related Stress, aimed to equip learners with the requisite skills, knowledge and competences to manage their own personal levels of work-related stress; while the second module, Environment-Centred Management of Work-Related Stress, was tailored towards helping learners create an ergonomically less-stressful working environment.

The course was hosted on a Moodle platform and delivered entirely asynchronously. As such, upon registration, learners were provided with access to a series of interactive slide presentations, additional support material and a link to submit their completed assessment activities. Learners also had access to a dedicated tutor and weekly skype meetings should they require additional synchronous learning support. The programme was underpinned by a philosophy of learner-centredness. As such, asynchronous nature of the programme meant that learners could progress through the programme at their own pace and submit their assessments as and when they completed them.

A specific pedagogical approach - Multiple Intelligence Teaching Approaches (MITA) was integrated into the programme design to address different learner abilities and intellectual dispositions (Denny et al., 2008). The approach encompasses a wide variety of teaching strategies which were integrated into both the learning material presentation and the learning activities. For example, inter and intra personal skills were targeted by encouraging learners to reflect on and evaluate the impact of the programme content on their personal circumstances and discuss this with others in the workplace, while visualspatial skills were targeted through visual presentations, graphs, mind-mapping and visualisation. Utilising MITA as the pedagogical framework was particularly suited to a 
DELAROSE: A Case Example of the Value of Embedded Course Content and Assessment in the

\section{Workplace}

European context as it takes account of both individual and cultural learning differences to achieve a shared outcome (Weber, 2005). The MITA approach facilitated the concurrent assessment of several work based competences through problem-based work integrated activity.

\section{Programme Assessment}

Achievement of the programme learning outcomes was assessed through the submission of a series of work-based activities contained within a personal portfolio of achievement. These activities were completed incrementally as the learner progressed through each Unit of Learning Outcomes and could be submitted at any time following course registration up until the closing date.

This approach, building upon learners previous experiences, engaged them in a series of tasks and activities associated with the units of learning. Learners were encouraged to reflect upon what they had learned, with reference to their own previous experiences. In this context, learners were required to submit evidence that they had carried out specific tasks or activities within their workplace, and reflect upon the suitability, sustainability and impact of these tasks on both their personal levels of work-related stress and the level of ergonomic stress within their own workplace.

For example, as part of the Unit of Learning 'The Organisation and Stress' learners were required to complete the 'Ten Category' assessment framework to evaluate the extent to which the organisational structures and policies contributed to work-related stress. Engaging with this assessment framework enabled learners to demonstrate that they had achieved several key specified learning outcomes within their own real-world context, relating to Knowledge: e.g., 'Knowledge of a framework to identify causes of stress at your workplace; Skills: e.g., 'Application of the 'Ten Category Framework'; and Competences: e.g., 'Identify the different categories of stress in your workplace'. Similarly, as part of the Unit of Learning 'Learning How to Relax', learners were required to complete and submit a $\log$ of their experiences of trialling series of relaxation exercises. The completion of this activity $\log$ enabled learners to demonstrate that had achieved the requisite learning outcomes for the Unit as these relate to Knowledge: e.g., ' Identify different relaxation methods'; Skills: e.g., 'Be able to use guided relaxation', and Competences: e.g., 'Adapt relaxation techniques to be utilised in the workplace'.

\section{Learner Feedback}

Feedback relating to the perceived quality and utility of the DELAROSE programme was collected from all 15 learners. This feedback was provided both quantitatively (through the completion of pre and post course questionnaires) and qualitatively (through the submission of written responses to a series of open-ended questions). 


\subsection{Quantitative Measures}

All learners completed questionnaires before commencing the online learning programme (T1) and after they had completed the programme (T2). The first questionnaire included measures to ascertain participants' knowledge and confidence in managing their own stress in the workplace and other people's' stress. The second questionnaire included these measures plus additional measures to ascertain the degree to which people found the different modules helpful in increasing their knowledge of these areas of stress management, and the degree to which they had implemented their knowledge in the workplace; as well as the degree to which they found the programme to be a useful and worthwhile learning experience.

\subsection{Qualitative Insights}

Learners were also asked to submit written feedback upon completion of the pilot course. This feedback was submitted electronically by the learners, and guided by the following statements:

1. Please tell us about the positive aspects of the course

2. Please tell us about the aspects of the course you thought could be improved

3. If you have found the course to be useful, please describe how you have used the knowledge you have gained in the course, in your workplace

\section{Results}

The quantitative data overall revealed a high degree of satisfaction. For example, there were significant increases in learner's knowledge $(p=.022)$ and in their in confidence in managing other people's workplace stress $(\mathrm{p}<0.001)$. 
DELAROSE: A Case Example of the Value of Embedded Course Content and Assessment in the

Workplace

Table 1. Impact of Pilot Programme of Learner Knowledge and Confidence

\begin{tabular}{llllll}
\hline Measure & $\begin{array}{c}\text { Mean before } \\
\text { pilot (SD) }\end{array}$ & $\begin{array}{c}\text { Mean after } \\
\text { pilot (SD) }\end{array}$ & t & P value & 95\% CI \\
\hline Knowledge & $8.1(1.0)$ & $8.7(1.0)$ & -2.59 & .022 & -1.2 to -0.1 \\
$\begin{array}{l}\text { Confidence in managing } \\
\text { own workplace stress }\end{array}$ & $5.6(1.1)$ & $5.8(0.9)$ & -1.00 & .334 & -.6 to 0.2 \\
$\begin{array}{l}\text { Confidence in managing } \\
\text { others' workplace stress }\end{array}$ & $4.6(1.0)$ & $5.8(0.9)$ & -6.00 & .000 & -1.6 to -0.8 \\
\hline
\end{tabular}

\subsection{Satisfaction with the Course}

Content \& Format of Course

$86.7 \%$ of participants reported satisfaction with the course $(n=13)$, rating it $>=5$ on a scale of 1 to 7 . The lowest rating of satisfaction was a score of 4 as rated by 2 participants.

93.3\% of participants agreed that they found the course helpful for learning techniques to manage their own stress $(n=14)$. The lowest rating of agreement with the utility of this aspect of the course was 4 , as rated by 1 participant (also on a scale of 1 to 7 ).

\subsection{Qualitative Feedback}

Learners identified several positive aspects of the course. In particular, increased selfawareness of stress, both in terms of the nature of stress and its impact; flexibility and ease of access, and the comprehensive range of information provided were identified as key positive aspects of the course.

"Interesting content for a wide range of professionals; to learn more about the influences of stress”

"Perfect prepared course material and comprehensive tasks"

"Learning material helpful and easy to understand"

Learners also identified aspects of the learning programme which could be improved. These related to timeframe of course completion (e.g. a loosely structured "guide" timeframe for completion of the different aspects of the course may be helpful), a reorganisation of course material and changes in format with regard to feedback:

"More interaction/discussion with students" 
"To provide learning material in a different way, with Powerpoint slides and additional learning material in one file and more graphically with more pictures and graphs."

"Feedback after completing tasks would be helpful and motivating - to know what needs to be improved."

In addition to this, we requested learner feedback as this relates to the application of knowledge for managing the learners personal levels of stress in the workplace stress, and in creating a less stress working environment.

With regard to the application to self, learners identified various positive personal benefits, including a deeper understanding of leadership styles within the workplace and the importance of accurate and effective appraisal of stressors:

"The person-centred modules provided me with more reflective opportunity and.... gave me an insight into, for example, management/leadership styles and I am now more aware of this and can see it in myself, my peers and management. I feel it has helped manage situations better when dealing with people, opened my eyes in a away",

"Owning stress and taking responsibility for it; able to stand back, analyse and respond more effectively."

"Become more proactive in managing stress, identifying triggers and putting action into place”

With regard to the application to others, learners highlighted improved communication with colleagues and the sharing of coping techniques:

"Encouraging staff teams to address stress in a supportive and open manner"

"Discussion with colleagues and proposing the use of relaxation exercises to reduce stress"

"Ergonomics - more aware of them and encouraging others to use good ergonomic practice."

"Staff member appeared very withdrawn and under pressure, due to take leave and requested at late notice to add an additional 2 days to end of their leave. 
DELAROSE: A Case Example of the Value of Embedded Course Content and Assessment in the Workplace

Normally not permitted. Aspects of stress and effects was at forefront of mind, so took decision to grant additional leave and worked around this with other staff"

"In our organisation, we have improved our communication to staff with memo's, staff updates and meetings frequency increased."

\section{Conclusion}

The results from the student feedback would suggest that learners greatly benefitted from the location of assessment activity within their own day to day working context. This made assessment more relevant to them and also impacted upon their own sense of achievement beyond the theoretical. It is interesting to note that where they critique the programme this related more to a desire for more structured guidance on when to submit assignments and greater interactivity with other learners. As a consequence the course has been adjusted to incorporate this critique for change.

\section{References}

Denny, M., Weber, E. F., Wells, J., Stokes, O. R., Lane, P., \& Denieffe, S. (2008).Matching purpose with practice: Revolutionising nurse education with MITA.Nurse Education Today, 28(1), 100-107.

European Agency for Safety and Health at Work (2010) ESENER - European Survey ofEnterprises on New and Emerging Risks. Publications Office of the EuropeanUnion, Luxembourg.

European Agency for Safety and Health at Work (2010) European Opinion Poll onOccupational Safety and Health. Publications Office of the EuropeanUnion,Luxembourg

European Commission, (2011) Commission Staff Working Paper Report on theimplementation of the European social partners' Framework Agreement on Workrelated Stress Brussels EC

Health and Safety Executive, (2014) Stress related and psychological disorders inGreat Britain 2014 http://www.hse.gov.uk/Statistics/causdis/stress/index.htm

Ridge, M., Wells, J., Denny, M., Cunningham, J., \& Chalder, T. (2011). Developing a webbased stress management intervention for occupational support workers. Journalof Mental Health, 20(2), 185-197.4

Schraer, R. (2014) Six out of 10 social workers would not recommend their workplaceCommunity Care http://www.communitycare.co.uk/2014/10/01/six 10socialworkers-recommend-workplace/

SECO, (2010). Stressstudie 2010: Stress bei Schweizer Erwerbstätigen, Zusammenhängezwischen Arbeitsbedingungen, Personenmerkmalen, Befinden und Gesundheit.Eidgenössisches Volkswirtschaftsdepartement EVD, Bern.

Weber, E. (2005). MI strategies in the classroom and beyond: using roundtable learning. New York, Pearson Publishers. 
Wells, J. S.G; Bergin, M.; Ryan, C.

Wells, J.S. (2011) Guest Editorial: The Impact of Stress Amongst HealthProfessionals Journal of Mental Health 20(22)111-114

Wells, J., Denny, M., \& Cunningham, J. (2011). Work related stress and European policyA comparative exploration of contextual stressors in the rehabilitation sector infive European countries. Journal of mental Health, 20(2), 165-173.

Wells, J., \& White, M. (2014). The impact of the economic crisis and austerity on the nursing and midwifery professions in the Republic of Ireland-'boom', 'bust' andretrenchment. Journal of Research in Nursing, 19(7-8), 562-577. 